Dokuz Eylül Üniversitesi-Mühendislik Fakültesi

Fen ve Mühendislik Dergisi

Cilt 20, Sayı 60, Eylül, 2018
Dokuz Eylul University-Faculty of Engineering Journal of Science and Engineering Volume 20, Issue 60, September, 2018

\title{
İki Eksenli Esnek bir Manipülatörün ANSYS APDL ile Modellenmesi ve Titreşim Kontrolü
}

\author{
Şahin YAVUZ ${ }^{* 1}$ \\ 1Dokuz Eylül Üniversitesi, Mühendislik Fakültesi, Makina Mühendisliği Bölümü, 35397, İzmir \\ (ORCID: 0000-0001-9007-772X)
}

(Alınış / Received: 20.01.2018, Kabul / Accepted: 18.04.2018, Online Yayınlanma / Published Online: 15.09.2018)

Anahtar Kelimeler Özet: Bu çalışmada, iki eksenli esnek bir manipülatörün hareket Esnek Manipülatör, Titreşim Kontrolü, sonrası artık titreşimlerinin kontrolü incelenmiştir. Manipülatör ANSYS'de APDL (Ansys Parametrik Tasarım Dili) kullanılarak modellenmiştir. Hareket sonrası titreșim sinyalleri, sonlu elemanlar teorisine dayalı olarak ANSYS'de gerçekleştirilen dinamik analiz ile simüle edilir. Önceki çalıșmada elde edilen deney sonuçları da sunulmuş ve benzetim sonuçları ile karşılaștırılmıştır. Tahrik motorları için trapez hız profilleri kullanılmıştır. Trapez hız profilinin ivme, sabit hız ve yavaşlama süreleri, durdurma pozisyonundaki manipülatör yapısının en düşük doğal frekansı dikkate alınarak seçilir. Çeşitli başlangıç ve durma pozisyonları değerlendirilmiştir. Hareket bittikten sonra meydana gelen artık titreşim sinyallerinin karelerinin ortalamasının karekök (RMS) değerleri hesaplanır. Artık titreşimin yavaşlama süresine duyarlı olduğu gözlemlenmiştir. RMS değerleri, yavaşlama süresinin tersi ilk doğal frekansa eşitse, en düşük değer elde edilmektedir. Yavaşlama zamanının tersi ilk doğal frekansın yarısına eşitse, en yüksek değer elde edilir. Benzetim ve deney sonuçlarının birbirleriyle uyumlu çıktığı görülmektedir.

\section{Modeling and Vibration Control of a Two-Link Flexible Manipulator with ANSYS APDL}

\section{Keywords}

Flexible

Manipulator, Vibration Control, ANSYS APDL

\begin{abstract}
In this study, the control of post-motion residual vibrations of a two-link flexible manipulator is investigated. The manipulator is modeled in ANSYS by using APDL (Ansys Parametric Design Language). The post-motion vibration signals are simulated by transient analysis which is performed in ANSYS based on the finite element theory. Experimental results are also presented and compared with simulation results. Trapezoidal velocity profiles are used for the motors. The acceleration, constant velocity and deceleration time intervals of the trapezoidal velocity profile are determined by considering the lowest natural frequency of the manipulator structure at the stopping position. Various starting and stopping positions are


considered. The root mean square (RMS) acceleration values of the vibration signals after stopping are calculated. It is observed that the residual vibration is sensitive to the deceleration time. The RMS values are lowest if the inverse of the deceleration time is equal to the first natural frequency. It is highest if the inverse of the deceleration time is equal to the half of the first natural frequency. It is observed that simulation and experimental results are in good agreement.

*Sorumlu yazar: sahin.yavuz@deu.edu.tr

\section{Giriş}

Robot manipülatörlerinin esnekliği, ağırlık, boyut, yük miktarı ve manipülatörlerin hızı gibi parametrelere bağlıdır. Manipülatörlerde esnekliğin etkisi hem hareket esnasinda hem de hareket bittikten sonra meydana gelen titreşimler olarak değerlendirilir. Hareketi bitirdikten sonra meydana gelen titreşimlere artık titreşimler adı verilir. Artık titreşimler, bitiş noktasındaki doğruluğu ve düzenli rejim süresini de etkiler. $\mathrm{Bu}$ tür manipülatörlerin performansı veya tekrarlanabilirlik, yüksek hızlı mühendislik uygulamalarında azalır. Artık titreşimleri azaltmak, pasif veya aktif gibi farklı kontrol stratejileri uygulayarak mümkündür.

İlk adım, manipülatörlerin matematiksel modellerini

Manipülatörlerin geliştirmektir. matematiksel modelleri, sonlu elemanlar yöntemi veya analitik yöntemlerle olușturulabilir. Çok eksenli esnek manipülatörlerin kontrolü uç nokta konumu ve yörünge takibinin kontrol hedeflerini göz önüne alarak incelenmiştir [1]. Dinamik sistemlerin türetilmiş diferansiyel denklemleri, sayısal yöntemler [2-4] veya ticari mühendislik programları [5] kullanılarak çözülebilir. Esnek manipülatörlerin dinamik analizi, tek eksenli, iki eksenli ve çok eksenli manipülatörleri sınıflandırarak detaylandırılmıştır [6].

Aktif veya pasif kontrol teknikleri, esnek robot manipülatörlerde kalıcı titreșimleri azaltmak için uygulanabilir. Aktif kontrol tekniği, aktüatör, sensör ve kontrol sistemi gerektirirken pasif kontrol tekniği, herhangi bir ek donanım kullanmadan hareket komutlarıyla gerçekleștirilebilir. Kapalı döngü olarak aktif kontrol elde edilirken, pasif kontrol açık döngü şeklinde gerçekleștirilebilir.

Esnek manipülatörün hem tek hem de iki eksenlik aktif kontrolü literatürde çalışılmıştır [7-11]. Bu çalışmaların çoğu piezoelektrik (PZT) aktüatörler kullanarak esnek manipülatörlerin titreşim genliklerini azaltmayı hedeflemektedir. Shin ve Choi [7] PZT aktuatörler ve sensörler ile iki eksenli bir esnek manipülatörün konum kontrolünü incelemişlerdir. Lagrange denklemi ve kayan mod denetleyicisi kullanarak atalet etkisi içeren doğrusal olmayan bir model oluşturmuşlardır. Gurses ve ark. [8] sonlu elemanlar teorisine dayanan PZT aktüatörler ile tek eksenli esnek manipülatörün titreşim kontrolü üzerinde çalışmışlardır. Fiber optik sensörle geri bildirim sağlayan PD tabanlı hı kontrol tekniklerini önermişlerdir. Mirzaee ve ark. [9] yörünge takibi için Lyapunov tabanlı kontrol cihazı kullanarak PZT aktüatör ve sensörlü iki eksenli bir manipülatörün aktif kontrolünü araștırmışlardır. Zhang ve ark. [10] rijit-esnek yapılı üç ayaklı paralel manipülatör üzerinde titreşim kontrolünü PZT sensör ve aktuatör kullanarak gerçekleștirmişlerdir. Manipülatörün birinci ve ikinci mod şeklini dikkate alarak \%65 oranında artık titreșimleri sönümlemeyi başarmışlardır. Pedro ve Smith [11] gerçek zamanlı 
hibrit PID ve yinelemeli öğrenme kontrolü uygulayarak iki eksenli esnek manipülatörde titreşim kontrolü üzerine çalışmışlardır.

Bazı çalışmalar, artık titreşimleri azaltmak için uygun yörüngeleri tasarlamak ve seçmek ile ilgilidir. Park [12] tork kısıtlamaları altında bir yolu tasarlamak ve optimize etmek suretiyle iki eksenli manipülatörün artık titreşiminin kontrolü üzerinde çalışmıştır. Abe [13], Lagrangian yaklaşımı ve varsayılan modlar yöntemini kullanarak, iki eksenli katıesnek bir çubuğun artık titreşiminin azaltılması için optimal bir yörünge planlaması da önermiștir. Green ve Sasiadek [14], uç nokta yörüngesinin izlenmesi için iki eksenlik manipülatör ile LQR ve bulanık mantık gibi kontrol yöntemlerini sunmuşlardır.

Esnek sistemlerin pasif kontrolü literatürde kapsamlı olarak incelenmiștir [15-17]. Artık titreşimi kontrol etmek için komut girdisi ön şekillendirme kullanılmıştır. Hareket girdisinde sistem frekansı ve sönümleme dikkate alınarak darbe dizisinin kullanılması, uç nokta titreșimini azaltır. Singer and Seering [15], bu yöntemi havacıllk alanına uygulamışlar ve darbelerin sayısını arttırarak yöntemin sağlamlığını geliștirmişlerdir. Girdi şekillendirme çalışmalarındaki ilerlemeler ve uygulama örnekleri Singhose [16] tarafından detaylı olarak incelenmiştir. Ouyang ve ark. [17] yapay sinir ağları yönetimini kullanmıșlar ve tek eksenli esnek bir manipülatörün titreşimlerini azaltmak için takviye öğrenme kontrolü üzerine çalışmışlardır.

Tek eksenli esnek manipülatörlerin pasif kontrolü literatürde yoğun olarak çalışılmıştır [18-21]. Bununla birlikte, iki eksenli veya çok eksenli manipülatörlerin pasif kontrolü ile ilgili sınırlı çalışmalar bulunmaktadır. Özer ve
Semercigil [22], kontrol tekniğini uygulamak için pasif bileşenlere sahip iki eksenli bir manipülatör üzerinde değişken kontrol tekniğinin etkisini göstermişlerdir.

Referanslarda [18-21], uygun bir yavaşlama zamanı seçilerek, tek eksenli manipülatörlerin artık titreşimleri kontrol edilebilir olduğu gösterilmiştir. Ankaralı ve Diken [18], Euler-Bernoulli kiriş teorisi ve mod toplamı teknikleri kullanılarak modellenen tek bir elastik bağlantıdaki geçici titreşim problemini çözmüşlerdir. Artık titreşimlerini azaltmak için bağlantıyı sikloidal bir hareketle sürmüşlerdir. Shin ve Brennan [19] herhangi bir kontrol algoritması düşünmeden problemi tek serbestlik dereceli bir sistemin temel uyarılmasina indirgeyen ötelenen veya döndürülen Euler-Bernoulli kirişinin kalıcı titreşimlerini kontrol etmek için iki basit yöntem önermişlerdir.

$\mathrm{Bu}$ çalışmada titreşim kontrolü iki eksenli bir esnek manipülatör üzerinde daha önce Karagülle ve ark. [23] tarafından yapılan çalışma esas alınarak farklı modelleme tekniği ile gerçekleştirilmiştir. Önceki çalışmada araştırmacilar sonlu elemanlar teorisine ve Newmark çözümüne dayanan bir MatLAB kodu geliştirerek uç nokta titreșim sinyallerinde benzetim çalıșması yapmışlardır. Bu çalışmada farklı olarak, manipülatörün bitiş noktası titreşimi ANSYS [24] kullanılarak benzetim çalışması yapılmıştır. Yayınlanan makalenin [23] çalışmasındaki deneysel sonuçlar kullanılmıştır. İki ekseni hareket ettiren motorlar için trapez hız profili girdileri kullanılmıştır. Hızlanma, sabit hız ve yavaşlama sürelerinin uç noktanın kalıcı titreşimi üzerindeki etkisi teorik ve deneysel olarak incelenmiştir.

\section{Materyal ve Metot}

İki eksenli manipülatör, metin dosyasına komutlar yazmanıza ve grafik arayüzü 
kullanmadan analiz yapmanıza olanak tanıyan APDL dili kullanılarak ANSYS'de modellenmiştir. Grafik arayüzü kullanılarak modellemede, model üzerinde bir hata olduğunda düzeltmek oldukça zordur. $\mathrm{Bu}$ nedenle APDL, bir model oluşturmak ve model üzerinde değișiklikler yapmak için çok daha kolay ve hızlı bir yoldur. Modellemede Timoshenko kiriş teorisine dayanan BEAM188 elemanı esnek bir kiriș olarak kullanılmıştır. Eleman her düğümde altı serbestlik derecesine sahiptir: $\mathrm{x}, \mathrm{y}$ ve $\mathrm{z}$ yönlerinde ötelemeler ve $\mathrm{x}, \mathrm{y}$ ve $\mathrm{z}$ ekseni etrafında dönmeler. Her eleman iki düğüm, kesit alanı, kesitin boyutları, alan atalet momenti, yükseklik ve malzeme özellikleriyle tanımlanır.

Çalışmada kullanılan iki eksenli manipülatörün modeli Şekil 1 (a) 'da gösterilmiştir. Uzuv-2, OB-kirişidir ve Uzuv-3, BC-kirişidir. Uzuv-2 0 noktası etrafinda Motor-2 tarafindan ve Uzuv-3 B noktası etrafinda Motor-3 tarafından döndürülmektedir. Motor-2'nin kütlesi 0 noktasında çerçeve üzerindedir. Motor3'ün kütlesi B noktasında Uzuv-2 üzerindedir. Uç nokta $C$ noktasıdır ve Uzuv-3 üzerindeki $C$ noktasında ağırlık vardır. Uzuv-2 ve Uzuv-3'ün anlık açısal pozisyonları sırasiyla $\theta_{2}$ ve $\theta_{3}$ ile ifade edilir. Uzuvların uzunlukları $\mathrm{L}_{2}=\mathrm{OB}$ ve $\mathrm{L}_{3}=\mathrm{BC}$ 'dir. Global orijin noktası 0 üzerindedir. Global kartezyen koordinatlar $\mathrm{x}, \mathrm{y}$ ve $\mathrm{z}$ 'dir.
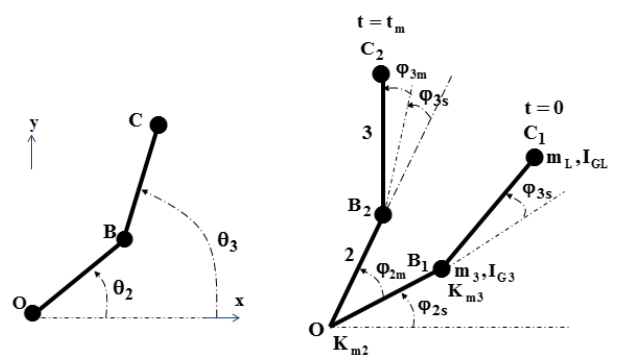

Şekil 1. İki eksenli manipülatörün (a) modeli ve (b) başlangıç ve durma pozisyonları.

Makalede tanımlanan bilgilere göre [23], düğ̈̈m numaraları APDL'de parametrik olarak tanımlanmıştır. Uzuv-2 ve Uzuv -3 için sonlu elemanlar sırasıyla $n_{\mathrm{e} 2}$ ve ne3'tür. Uzuv-2 için, $\mathrm{n}_{\mathrm{e} 2}=100$ ve Uzuv-3 için $\mathrm{n}_{\mathrm{e}}=115$ seçilmiştir. Şekil 1 (b) için $n_{e 2}=2$ ve $n_{e 3}=3$ olduğu görülmektedir. Analiz için seçilen sayılar, sonlu elemanlar sayısına göre genişletilebilir. Sensör noktası C noktasından $85 \mathrm{~mm}$ uzakta bulunması nedeniyle, $\mathrm{n}_{\mathrm{e}}$ sensör noktasının düğüm sayısına uyacak şekilde 115 olarak seçilmiştir.

APDL'de iki farklı kesit alanı tanımlanmıştır, çünkü Uzuv-2 ve Uzuv-3, Tablo 2'de verilen farkl kesitlere sahiptir. İki farklı kesite sahip Beam188 elemanları, Uzuv-2 ve Uzuv-3'e ilișkin dügümler arasında atanır.

Motor-2 ve Motor-3'e karşıllk gelen 0 ve B noktalarında sırasıyla iki dönel mafsal olduğu için, bu noktalarda pilot düğümler TARGE170 elemanları ile tanımlanır ve atanır. TARGE170, ilgili temas elemanlarında çeşitli 3 boyutlu hedef yüzeyleri temsil etmek için kullanılır. Hedef segment elemanları üzerinde herhangi bir doğrusal veya dönel yer değiştirme uygulanabilir. Rijit bir yüzeyin her hedef kısmı belirli bir şekil veya segment türüne sahip tek bir elemandır. Segment türleri çeşitli düğümler ve TSHAP komutu ile tanımlanır. TSHAP komutu elemanın geometrisini gösterir. TSHAP tanımını değiștirerek TARGE170 öğesi için sekiz farklı segment tipi desteklenmektedir: 3 düğüm üçgen, 4 düğüm dörtgen, 6 düğüm üçgen, 8 düğüm dörtgen, silindir, koni, küre ve pilot düğ̈̈m. Sadece pilot dügümlerin $\mathrm{x}, \mathrm{y}$ ve $\mathrm{z}$ ekseni etrafinda dönme serbestlik dereceleri vardır. Ayrıntılı bilgi ANSYS Teori Referansı'nda bulunabilir [24].

APDL'de kullanılan diğer eleman tipi, dönel mafsal tanımlamasını sağlayan MPC184 elemanıdır. MPC184 elemanlar ailesi, çoklu cisim mekanizmasında esnek ve katı bileșeni birbirine bağlar. MPC184 
eklem elementi, her düğümde altı serbestlik derecesi bulunan iki düğüm tarafından tanımlanır. İki düğüm arasındaki bağıl hareket, altı adet bağll serbestlik derecesi ile ifade edilir. Uygulamaya bağlı olarak, altı adet bağıl serbestlik derecesinin herhangi birine veya bir kısmına uygun kinematik kısıtlamaları uygulayarak, farklı türdeki eklem unsurları yapılandırılabilir. Örneğin, dönen bir eklemi taklit etmek için üç bağıl yer değiştirme serbestlik derecesi ve iki bağll dönme serbestlik derecesi sınırlandırılmış ve yalnızca bir bağıl dönme serbestlik derecesi sağlanmıştır. MPC184 elemanlarının bazı ortak tipleri Tablo 1'de verilmektedir.

Tablo 1. MPC184 elemanın özellikleri

\begin{tabular}{cccc}
\hline Eklem Tipi & $\begin{array}{c}\text { Keyopt } \\
\text { ion (1) }\end{array}$ & $\begin{array}{c}\text { Keyopt } \\
\text { ion (4) }\end{array}$ & $\begin{array}{c}\text { Sinırlam } \\
\text { alar }\end{array}$ \\
\hline Dönel & 6 & - & 5 \\
Z-eksen & 6 & 1 & 5 \\
Dönel & & & 4 \\
Universal & 7 & - & 5 \\
Öteleme & 10 & - & 3 \\
Küresel & 5 & - & 4 \\
Silindirik & 11 & - & 4 \\
Z-eksen & 11 & 1 & \\
Silindirik & & & \\
\hline
\end{tabular}

MPC184 elemanı, Keyoption (1) seçeneğini 6 ve Keyoption (4) seçeneğini 1 olarak tanımlanırsa, bu eleman türünü dönel mafsal olarak tanımlayarak $\mathrm{Z}$ ekseni etrafında kirişi döndürmeye izin verir. Bu yüzden, MPC184 elemanı O ve B noktaları ile ilgili dügümlere atanan iki pilot düğüm arasında tanımlanmıştır. Motorun eklem esnekliğine sahip olması nedeniyle motorun dönel yay sabiti 16000 Nm / rad olarak atanmıştır.

ANSYS'deki analizin akış şeması aşağıda özetlenmiştir.

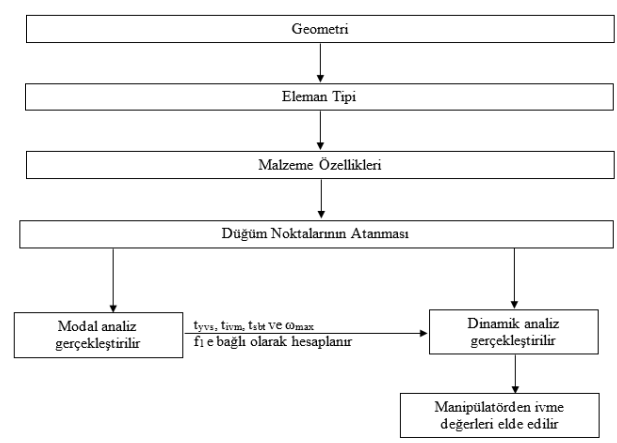

Şekil 2. ANSYS'de gerçekleștirilen analizin akış șeması

Malzeme yapısına bağlı olarak sönüm değerleri değişmektedir ve titreşim sinyallerini realize edebilmek için sönümü dikkate almak gerekir. Bu çalışmada sönümü dikkate almak için Rayleigh sönüm yöntemi kullanılmıştır. Rayleigh sönümü aşağıdaki denklemle ifade edilir.

$$
\mathbf{c}_{\mathrm{s}}=\eta \mathbf{m}_{\mathrm{s}}+\beta \mathbf{k}_{\mathrm{s}}
$$

Burada, $\eta$ ve $\beta$ sırasıyla kütle ve rijitlik matrisi katsayılarını ifade eden sönüm katsayılarıdır [25].

\subsection{Hareket Girdisi}

İki eksenli manipülatörün hareketi Şekil 1 (b) 'de gösterilmiştir. Manipülatör, $\mathrm{t}=0$ 'da bir başlangıç konumundan $\left(\mathrm{OB}_{1} \mathrm{C}_{1}\right), \mathrm{t}=\mathrm{t}_{\mathrm{m}}$ 'de bir bitiş konumuna $\left(\mathrm{OB}_{2} \mathrm{C}_{2}\right)$ hareket eder, burada $t$ zaman ve $\mathrm{t}_{\mathrm{m}}$ hareket zamanıdır. İlk açısal pozisyonlar $\mathrm{t}=0$ 'da $\theta_{2}=\varphi_{2 \mathrm{~s}}$ ve $\theta_{3}=\varphi_{2 \mathrm{~s}}+$ $\varphi_{3 \text { s }}$ olarak verilir. Durma zamanındaki açısal konumlar $\mathrm{t}=\mathrm{t}_{\mathrm{m}}{ }^{\prime} \mathrm{de} \theta_{2}=\varphi_{2 \mathrm{~s}}+\varphi_{2 \mathrm{~m}}$ ve $\theta_{3}=\varphi_{2 \mathrm{~s}}+\varphi_{2 \mathrm{~m}}+\varphi_{3 \mathrm{~s}}+\varphi_{3 \mathrm{~m}}$ olarak verilir.

Motorlar, Şekil 3'te verilen trapez hız profilini takip etmektedir. Şekil 3'te verilen profile göre darbe üreten hareket kontrol üniteleri piyasada mevcuttur. Hız eğrisinin altındaki alan, $\varphi_{2 \mathrm{~m}}$ ve $\varphi_{3 \mathrm{~m}}$ motor rotasyonlarını verir. 


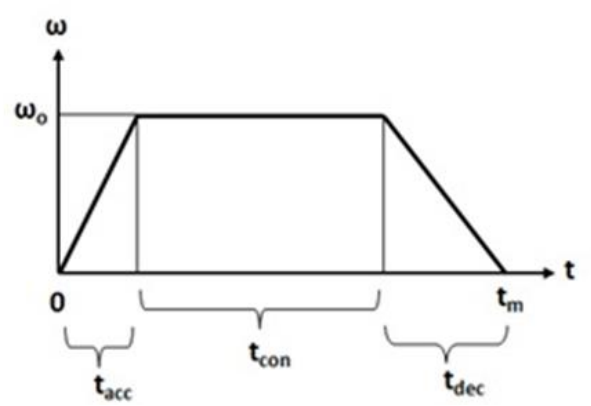

Şekil 3. Motorlara verilen hareket girdisi

C noktasindan $\mathrm{d}_{\mathrm{alg}}$ mesafesindeki sensor noktasının titreşimi analiz edilir. X-y düzleminde (hareket düzlemi) BChattına dik titreşim yönü incelenmiştir.
Sensör noktasının titreşim yönündeki yer değiştirmesinin $d_{R}$ olduğunu varsayarsak $d_{R}$ 'nin ikinci türevi ivme sinyalidir ve $a_{R}$ ile gösterilir. Yerçekimi ivmesi $\mathrm{z}$ yönündedir ve bu nedenle dahil edilmemiştir.

$\mathrm{Bu}$ çalışmada ANSYS tarafindan elde edilen benzetim sonuçları için Tablo 2'de verilen değerler alınmıştır. Sayısal değerlerin atanmasında Şekil 4'de verilen deney sistemi dikkate alınmıştır. Malzeme, geometrik, atalet ve dönel yayın değerleri, deneysel sistemde kullanılan değerlere karşılık gelir.

Tablo 2. Deneysel sistemin özellikleri

\begin{tabular}{|c|c|c|c|}
\hline Tanım & Değer & Tanım & Değer \\
\hline Elastisite Modülü & $\mathrm{E}_{2}=\mathrm{E}_{3}=71 \mathrm{GPa}$ & Yoğunluk & $\rho_{2}=\rho_{3}=2700 \mathrm{~kg} / \mathrm{m}^{3}$ \\
\hline $\begin{array}{l}\text { Rayleigh Sönüm } \\
\text { Katsayısı }\end{array}$ & $\begin{array}{c}\eta=0 \text { (kütle matrisi } \\
\text { katsayısı) }\end{array}$ & $\begin{array}{l}\text { Rayleigh Sönüm } \\
\text { Katsayısı }\end{array}$ & $\begin{array}{l}\beta=0.0003 \text { (rijitlik } \\
\text { matrisi katsayısı) }\end{array}$ \\
\hline $\begin{array}{c}\text { Sensör noktasının uç } \\
\text { nokta yükünden olan } \\
\text { uzaklığı }\end{array}$ & $\mathrm{d}_{\mathrm{alg}}=85 \mathrm{~mm}$ & Sonlu eleman sayısı & $\mathrm{n}_{\mathrm{e} 2}=100, \mathrm{n}_{\mathrm{e} 3}=115$ \\
\hline Uzuv-2 Uzunluk & $\mathrm{L}_{2}=465.5 \mathrm{~mm}$ & Uzuv-3 Uzunluk & $\mathrm{L}_{3}=575 \mathrm{~mm}$ \\
\hline Uzuv-2 Kesit Ölçüleri & $\mathrm{b}=80 \mathrm{~mm}, \mathrm{~h}=6 \mathrm{~mm}$ & Uzuv-3 Kesit Ölçüleri & $\mathrm{b}=60 \mathrm{~mm}, \mathrm{~h}=6 \mathrm{~mm}$ \\
\hline Kesit Alanı & $\mathrm{A}_{2}=480 \mathrm{~mm}^{2}$ & Kesit Alanı & $A_{3}=360 \mathrm{~mm}^{2}$ \\
\hline Alan Atalet Momenti & $\mathrm{I}_{2}=1440 \mathrm{~mm}^{4}$ & Alan Atalet Momenti & $\mathrm{I}_{3}=1080 \mathrm{~mm}^{4}$ \\
\hline Motor-3 Ağırlık & $\mathrm{m}_{3}=3.26 \mathrm{~kg}$ & $\begin{array}{c}\text { Motor-3 kütle atalet } \\
\text { momenti }\end{array}$ & $\mathrm{I}_{\mathrm{m} 3}=0.0134 \mathrm{~kg}-\mathrm{m}^{2}$ \\
\hline Uç nokta yükü ağırlığı & $\mathrm{m}_{\mathrm{L}}=0.40 \mathrm{~kg}$ & $\begin{array}{l}\text { Uç nokta yükü kütle } \\
\text { atalet momenti }\end{array}$ & $\mathrm{I}_{\mathrm{L}}=0.9 \times 10-4 \mathrm{~kg}-\mathrm{m}^{2}$ \\
\hline Motor dönel yay sabiti & $\begin{array}{c}\mathrm{K}_{\mathrm{m} 2}=\mathrm{K}_{\mathrm{m} 3}=16000 \\
\mathrm{Nm} / \mathrm{rad}\end{array}$ & Zaman Adımı & $\Delta \mathrm{t}=0.0025 \mathrm{~s}$ \\
\hline
\end{tabular}

Duruş zamanından sonra artık titreşimin izlendiği zaman $t_{a t z}$ ile gösterilmiştir. Dinamik analizde benzetim sonuçlarının elde edilene kadar geçen süre $t_{s}$ ile gösterilmiştir. Dolayısıyla, toplam süre $\left(t_{s}\right)$, hareket süresi $\left(t_{m}\right)$ ile artık titreşimin gözlendiği zamanın ( $\left.\mathrm{t}_{\mathrm{atz}}\right)$ toplamı olmaktadır. Așağıda verilen dinamik sonuçlar için, tatz 4 s olarak alınmıștır.

\subsection{Deneysel Sistem}

$\mathrm{Bu}$ çalışmada tasarlanan ve üretilen deneysel sistemin fotoğrafı Şekil 4'te gösterilmektedir. Deneysel sistem, uç nokta yüküne sahip, iki eksenli esnek bir manipülatörden oluşur. Mitsubishi Elektrik servo motor ve sürücü olarak 200 W, Model HC-KFS23B / MR-J2S-20A kullanılmıştır. Motor-2 ve Motor-3 için sırasıyla Harmonik tahrik dişli kutuları, HFUC-32-100 / 100 (dişli oranı: 100) ve HFUC-20-80 / 80 (dişli oranı: 80) dır. PC tabanlı hareket kontrol kartı, Adlink PCI-8366 kullanılmıștır. Hareket kontrol kartı ve sürücüler seri olarak SSCNET ağı ile bağlanır. Sürücüler, Adlink ActiveX bileşenini kullanarak Visual Basic komutlarıyla programlanır. 


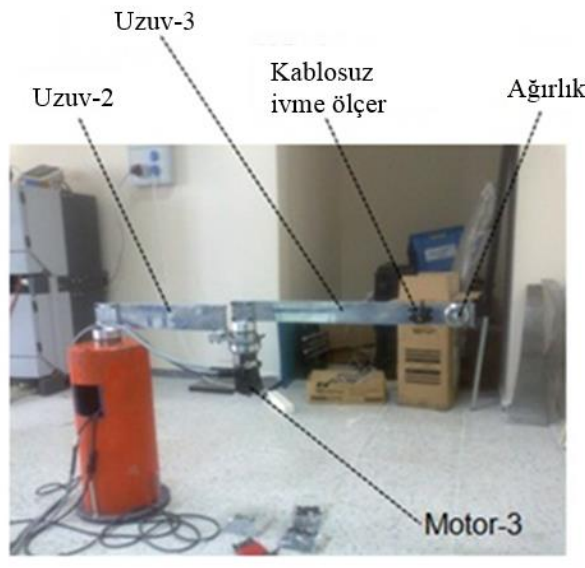

Şekil 4. Deneysel sistem
MicroStrain kablosuz veri toplama (WDA) sistemi [26], istenilen noktadaki deneysel ivme sinyallerini almak için kullanılır.

\section{Bulgular}

Esnek, yarı esnek ve katı olan ve Tablo 3'te listelenen sistemin üç duruş pozisyonu incelenmiştir. Bu pozisyonlar için birinci doğal frekansları tabloda verilmiştir.

Tablo 3. İncelenen pozisyonlarda birinci doğal frekanslar

\begin{tabular}{|c|c|c|c|c|c|c|}
\hline \multicolumn{2}{|c|}{ Durma Pozisyonua } & \multirow[b]{2}{*}{$\varphi_{2 \mathrm{~s}}$} & \multirow[b]{2}{*}{$\varphi_{3 \mathrm{~s}}$} & \multirow{2}{*}{$\begin{array}{c}\text { MATLAB } \\
\mathrm{f}_{1}(\mathrm{~Hz})\end{array}$} & \multirow{2}{*}{$\begin{array}{l}\text { Deney } \\
\mathrm{f}_{1}(\mathrm{~Hz})\end{array}$} & \multirow{2}{*}{$\begin{array}{l}\text { ANSYS } \\
\mathrm{f}_{1}(\mathrm{~Hz})\end{array}$} \\
\hline Pozisyon & Şekil & & & & & \\
\hline Pos-f & & $0^{\circ}$ & 0 o & 2.71 & 2.71 & 2.7059 \\
\hline Pos-s & & $45^{\circ}$ & $90^{\circ}$ & 3.21 & 3.31 & 3.2153 \\
\hline Pos-r & B & $90^{\circ}$ & $170^{\circ}$ & 4.17 & 4.22 & 4.1695 \\
\hline
\end{tabular}

${ }^{\text {a }} \varphi_{2 \mathrm{~s}} 0-360^{\circ}$ arası seçilebilir

İlk doğal frekans düştükçe sistem daha esnek hale gelir. Pos-f'nin Pos-s'dan daha esnek ve Pos-s'nin Pos-r'dan daha esnek olduğu gözlenmektedir.

Seçilen bir hareket için sistemin başlangıç ve durma pozisyonları vektörü, $\mathbf{q}_{\mathrm{p}}=\left[\begin{array}{lll}\varphi_{2 \mathrm{~s}}, & \varphi_{3 \mathrm{~s}}, \varphi_{2 \mathrm{~m}}, \varphi_{3 \mathrm{~m}}\end{array}\right]^{\mathrm{T}}$ ile tanımlanmıştır. Trapez hız profili, $\mathbf{q}_{\mathrm{m}}=[$ $\left.t_{\text {ivm }}, t_{\text {sbt, }} t_{y v s,} t_{m}\right]^{T}$ vektörü ile tanımlanmıştır. Üç zaman parametresi seçilir ve dördüncüsü $t_{m}=t_{\text {ivm }}+t_{\text {sbt }}+t_{y v s}$ denklemi ile hesaplanır. Hesaplanan zaman parametresi aşağıdaki $\mathrm{q}_{\mathrm{m}}$ vektöründe "*" ile gösterilmiştir.

Birimler aksi belirtilmediği sürece açllar için derece ve zaman için saniyedir.
Analiz için dört hareket durumu incelenmiştir. İncelenen hareketler Tablo 4'te listelenmiştir. Durum-ff için başlama konumu Pos-f, durma konumu Pos-f dir. Durum-fs için başlama konumu Pos-f, durma konumu Pos-s dir. Durum-fr için başlama konumu Pos-f ve durma konumu Pos-r'dir. Durum-sr için bașlama konumu Pos-s ve durma konumu Pos-r dir.

ANSYS'de modellenen üç farklı durma konumu Şekil 5'te gösterilmektedir. Esnek, yarı esnek ve rijit pozisyonlar sırasıyla Şekil 5 (a), (b) ve (c) 'de gösterilmektedir. 
Ş. Yavuz / İki Eksenli Esnek bir Manipülatörün ANSYS APDL ile Modellenmesi ve Titreşim Kontrolü

Tablo 4. İncelenen hareketler

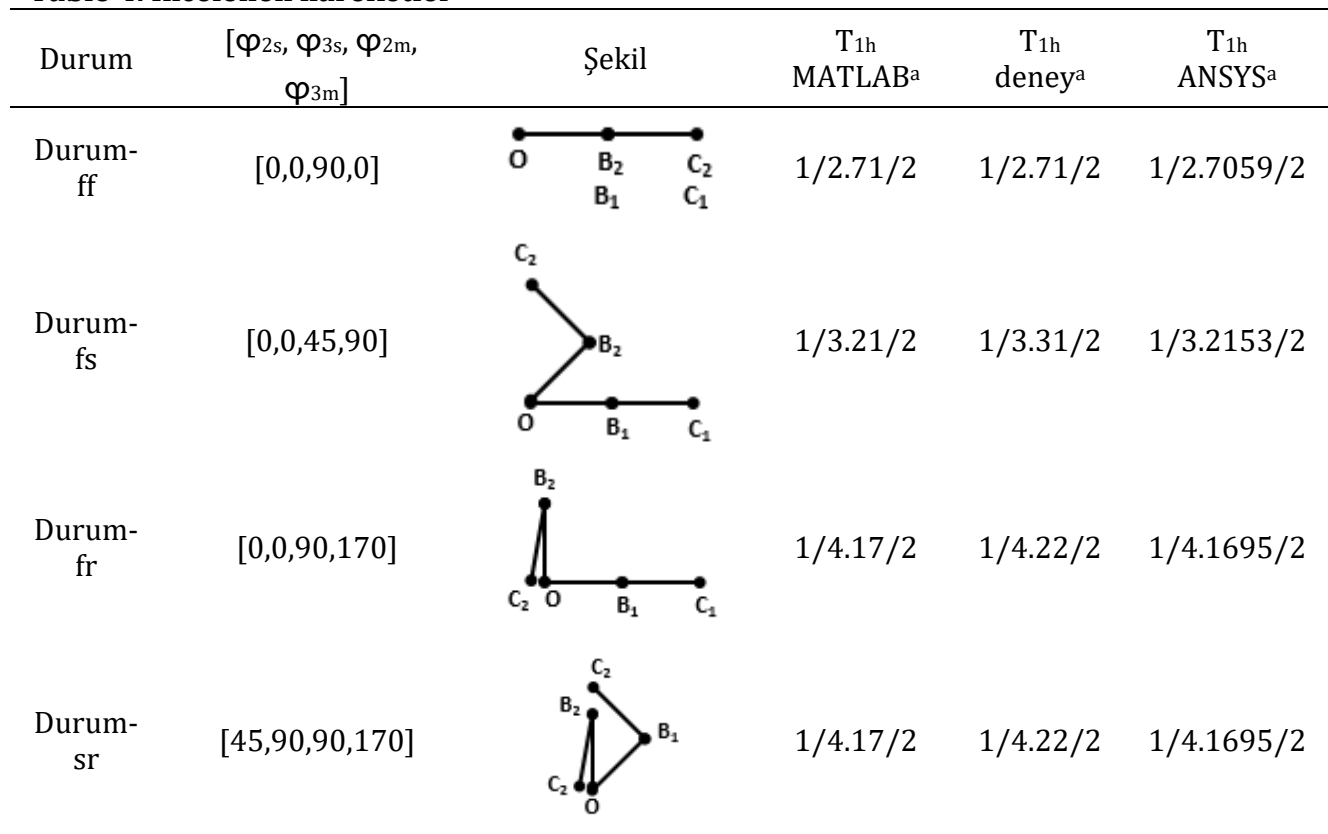

a $\mathrm{T}_{1 \mathrm{~h}}$ duruş pozisyonundaki ilk doğal frekans dikkate alınarak seçilmiştir.

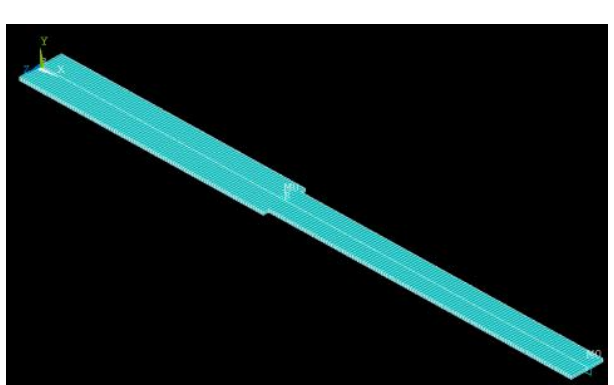

(a)

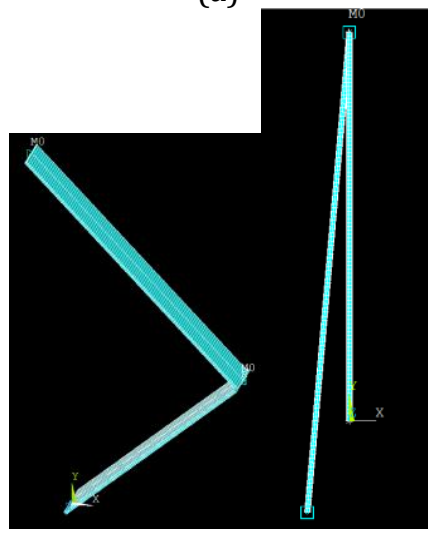

(b)

(c)

Șekil 5. Duruș pozisyonları (a) esnek, (b) yarı esnek ve (c) rijit
Önceki çalışmada elde edilen deney verileri [23] kullanılarak, ANSYS de yapılan benzetim çalışmasının kıyaslamalı sonuçları Şekil 6 ve Şekil 7 de verilmiștir.
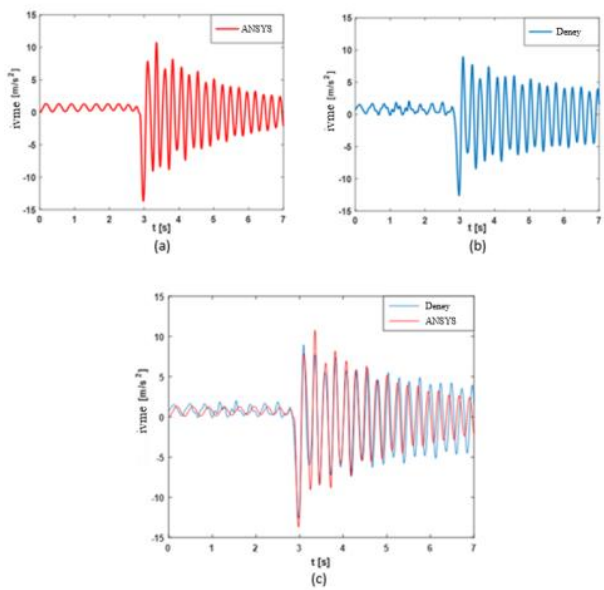

Sekil 6. Durum-fr için örnek titreșim sinyalleri [ $\left.\mathrm{t}_{\mathrm{ivm}}, \mathrm{t}_{\mathrm{sbt}}, \mathrm{t}_{\mathrm{yvs}}, \mathrm{t}_{\mathrm{m}}\right]=\left[{ }^{*}, \mathrm{~T}_{1 \mathrm{~h}}, \mathrm{~T}_{1 \mathrm{~h}}, 3\right]$ (a) ANSYS, (b) Deney, (c) ANSYS ve deney karşılaștırma.

$t_{m}<t \leq t_{m}+t_{a t z}$ için titreşim sinyallerinin penceresi artık titreşimleri analiz 
etmeye yöneliktir. Zaman değerleri, pencere için $t_{m}=3 \mathrm{~s}$ ve $t_{a t z}=4 \mathrm{~s}$ olarak alınır. Sinyalin karelerinin ortalamasının karekök (RMS) değeri pencerede hesaplanır. Farklı durumlarda ve farklı hız profilleri için RMS değerleri Tablo 5 'te listelenmiștir.
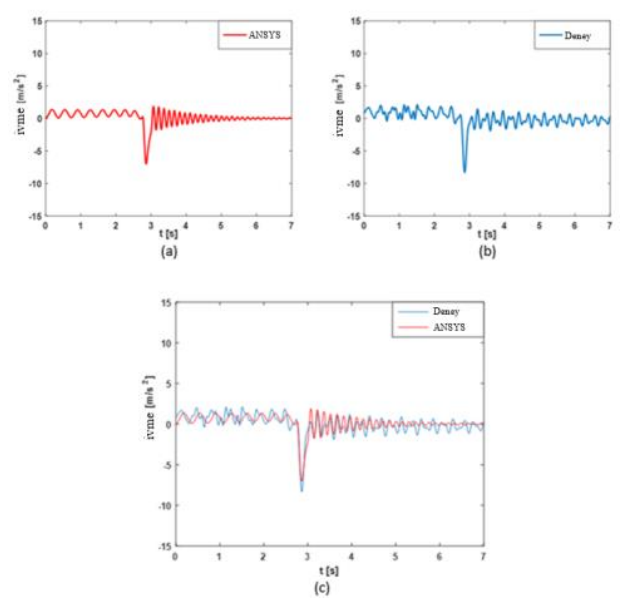

Şekil 7. Durum-fr için örnek titreșim sinyalleri [ $\left.\mathrm{t}_{\mathrm{ivm}}, \mathrm{t}_{\mathrm{sbt}}, \mathrm{t}_{\mathrm{yvs}}, \mathrm{t}_{\mathrm{m}}\right]=\left[{ }^{*}, \mathrm{~T}_{1 \mathrm{~h}}, 2 \mathrm{~T}_{1 \mathrm{~h}}, 3\right](\mathrm{a})$ ANSYS, (b) Deney, (c) ANSYS ve deney karşılaştırma.

Tablo 5. Farklı durumlar için ivme sinyallerinin RMS değerleri

\begin{tabular}{|c|c|c|c|c|c|c|c|}
\hline Durum & $\begin{array}{c}\text { [ tivm, tsbt, tyvs, } \\
\text { tm ] }\end{array}$ & $\begin{array}{l}\text { Benzetim } \\
\text { MATLAB }\end{array}$ & $\begin{array}{c}\text { Azalma } \\
\%\end{array}$ & Deney & $\begin{array}{c}\text { Azalma } \\
\%\end{array}$ & $\begin{array}{c}\text { Benzetim } \\
\text { Ansys }\end{array}$ & $\begin{array}{c}\text { Azalma } \\
\%\end{array}$ \\
\hline \multirow{4}{*}{$\begin{array}{l}\text { Durum- } \\
\text { ff }\end{array}$} & {$[*, \mathrm{~T} 1 \mathrm{~h}, \mathrm{~T} 1 \mathrm{~h}, 3]$} & 6.22 & - & 6.41 & 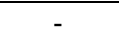 & 5.99 & - \\
\hline & {$\left[{ }^{*}, \mathrm{~T} 1 \mathrm{~h}, 2 \mathrm{~T} 1 \mathrm{~h}, 3\right]$} & 0.45 & 92.77 & 0.62 & 90.33 & 0.35 & 94.16 \\
\hline & {$\left[{ }^{*}, \mathrm{~T} 1 \mathrm{~h}, 3 \mathrm{~T} 1 \mathrm{~h}, 3\right]$} & 1.95 & 68.65 & 1.66 & 74.10 & 1.85 & 69.12 \\
\hline & {$\left[{ }^{*}, \mathrm{~T} 1 \mathrm{~h}, 4 \mathrm{~T} 1 \mathrm{~h}, 3\right]$} & 0.49 & 92.12 & 0.74 & 88.46 & 0.37 & 93.82 \\
\hline \multirow{4}{*}{$\begin{array}{l}\text { Durum- } \\
\text { fs }\end{array}$} & {$\left[{ }^{*}, \mathrm{~T} 1 \mathrm{~h}, \mathrm{~T} 1 \mathrm{~h}, 3\right]$} & 3.56 & - & 3.49 & - & 3.54 & - \\
\hline & {$\left[{ }^{*}, \mathrm{~T} 1 \mathrm{~h}, 2 \mathrm{~T} 1 \mathrm{~h}, 3\right]$} & 0.19 & 94.66 & 0.31 & 91.12 & 0.21 & 94.07 \\
\hline & {$\left[{ }^{*}, \mathrm{~T} 1 \mathrm{~h}, 3 \mathrm{~T} 1 \mathrm{~h}, 3\right]$} & 1.04 & 70.79 & 1.27 & 63.61 & 1.08 & 69.49 \\
\hline & {$\left[{ }^{*}, \mathrm{~T} 1 \mathrm{~h}, 4 \mathrm{~T} 1 \mathrm{~h}, 3\right]$} & 0.19 & 94.66 & 0.31 & 91.12 & 0.21 & 94.07 \\
\hline \multirow{4}{*}{$\begin{array}{l}\text { Durum- } \\
\text { fr }\end{array}$} & {$[*, \mathrm{~T} 1 \mathrm{~h}, \mathrm{~T} 1 \mathrm{~h}, 3]$} & 4.13 & - & 4.14 & - & 4.02 & - \\
\hline & {$\left[{ }^{*}, \mathrm{~T} 1 \mathrm{~h}, 2 \mathrm{~T} 1 \mathrm{~h}, 3\right]$} & 0.73 & 82.32 & 0.69 & 83.33 & 0.55 & 86.32 \\
\hline & {$\left[{ }^{*}, \mathrm{~T} 1 \mathrm{~h}, 3 \mathrm{~T} 1 \mathrm{~h}, 3\right]$} & 1.39 & 66.34 & 1.35 & 67.39 & 1.19 & 70.40 \\
\hline & {$\left[{ }^{*}, \mathrm{~T} 1 \mathrm{~h}, 4 \mathrm{~T} 1 \mathrm{~h}, 3\right]$} & 0.72 & 82.57 & 0.59 & 85.75 & 0.3 & 92.54 \\
\hline \multirow{4}{*}{$\begin{array}{c}\text { Durum- } \\
\text { sr }\end{array}$} & {$[*, \mathrm{~T} 1 \mathrm{~h}, \mathrm{~T} 1 \mathrm{~h}, 3]$} & 1.99 & 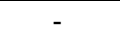 & 2.49 & 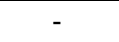 & 2.03 & - \\
\hline & {$\left[{ }^{*}, \mathrm{~T} 1 \mathrm{~h}, 2 \mathrm{~T} 1 \mathrm{~h}, 3\right]$} & 0.29 & 85.43 & 0.35 & 85.94 & 0.28 & 86.21 \\
\hline & {$\left[{ }^{*}, \mathrm{~T} 1 \mathrm{~h}, 3 \mathrm{~T} 1 \mathrm{~h}, 3\right]$} & 0.65 & 67.34 & 0.69 & 72.29 & 0.68 & 66.50 \\
\hline & {$\left[{ }^{*}, \mathrm{~T} 1 \mathrm{~h}, 4 \mathrm{~T} 1 \mathrm{~h}, 3\right]$} & 0.16 & 91.96 & 0.34 & 86.35 & 0.16 & 92.12 \\
\hline
\end{tabular}




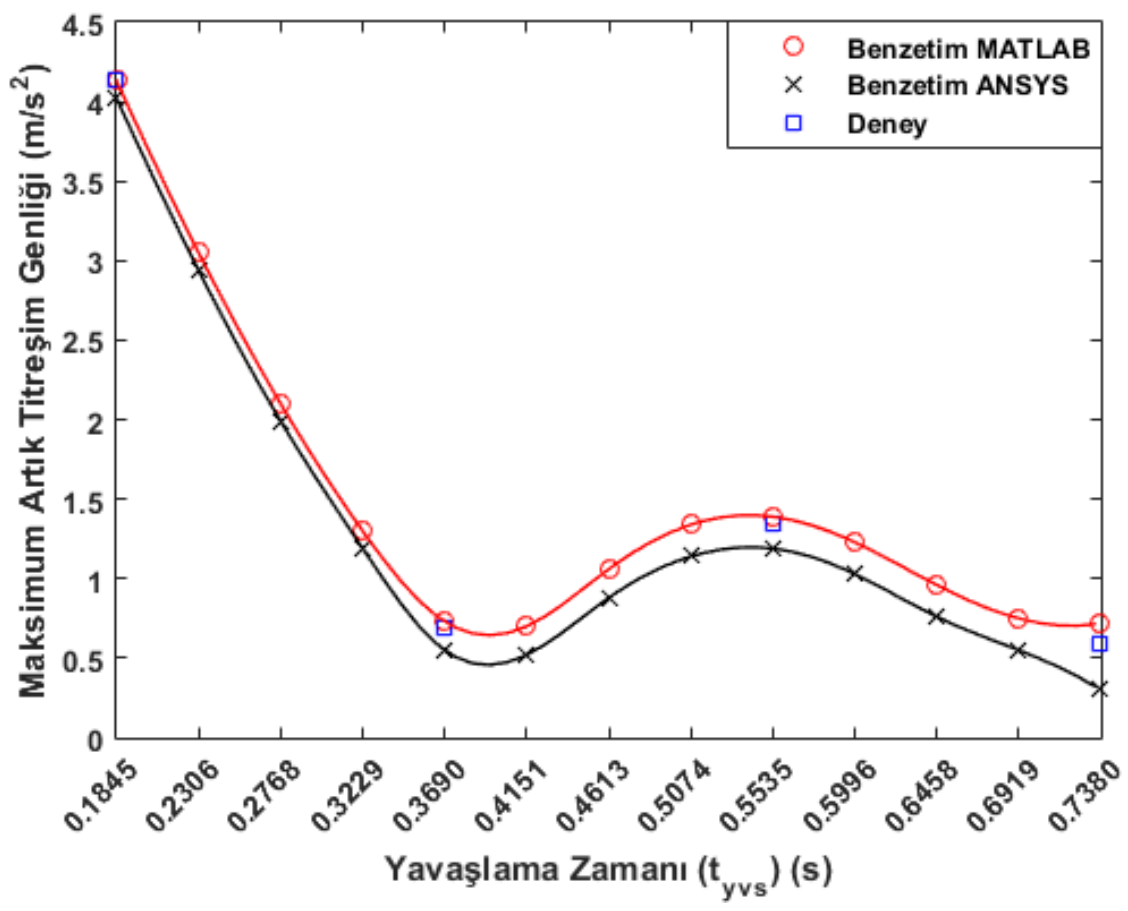

Şekil 8. Durum-fr için artık titreşim sinyallerinin RMS değerlerinin yavaşlama zamanına göre değişimini gösteren artık titreșim spektrumu

Yukarıdaki sekiller ve tablolardan ANSYS'deki dinamik analiz ile elde edilen benzetim sonuçlarının deneysel sonuçlar ile uyum içinde olduğu gözlemlenmiştir. RMS değeri, yavaşlama süresi $\mathrm{T}_{1 \mathrm{~h}}$ 'ye eşit olduğunda en yüksek değer elde edilmektedir.

Tablo 5 ve Şekil 8 'den, $2 \mathrm{~T}_{1 \mathrm{~h}}$ ve $4 \mathrm{~T}_{1 \mathrm{~h}}$ için esnek manipülatörün tüm durma konumlarında titreşim azaltılmasının yapılabileceği görülmektedir. $2 \mathrm{~T}_{1 \mathrm{~h}}$ için azalma miktarı Durum-ff için MATLAB'da elde edilen benzetim çalışmasında \% 92.77, Durum-ff için ANSYS'de elde edilen benzetim çalışmasında \% 94.16 iken, Durum-ff için yapılan deneyde \% 90.33'tür. $2 \mathrm{~T}_{1 \mathrm{~h}}$ için, azalma miktarı Durum-fr için MATLAB'da elde edilen benzetim çalışmasında \% 82.32 ve Durum-fr için ANSYS'de elde edilen benzetim çalıșmasında \% 86.32 iken, Durum-fr için yapılan deneyde \% 83.33'tür. Benzer azalma miktarları $4 \mathrm{~T}_{1 \mathrm{~h}}$ için de sağlanabilir. Trapez hareket profillerinde yüksek hızlı uygulamalar gibi robot manipülatörünün kısa hareket süreleri için $2 \mathrm{~T}_{1 \mathrm{~h}}$ yavaşlama süresi $4 \mathrm{~T}_{1 \mathrm{~h}}$ 'den daha iyidir. Sonuçlardan, esnek durdurma konumundaki titreşim azalmasının sert durma konumundan daha iyi olduğu ifade edilebilir. Deneysel sonuçlar, yaklașımın pratik mühendislik uygulamalarında robot manipülatörleri için başarılı olabileceğini göstermektedir.

\section{Tartışma ve Sonuc}

Esnek sistemlerin kalıcı titreşimleri, hız komut girdisi ön şekillendirme tekniği 
ile azaltılabilir. Sistem frekansı ve sönüm kestirimi göz önüne alınarak darbe dizileri kullanılır. $\mathrm{Bu}$ yöntem çeşitli yapılar için kapsamlı olarak incelenmiştir. Bir diğer yaklaşım sistemin doğal frekansı dikkate alınarak hız profilindeki yavaşlama süresini seçmektir. Bu yaklaşım, tek eksenli esnek manipülatör için geliştirilmiștir. Tek eksenli esnek manipülatörlerin titreșim kontrolü literatürde araştırılmıştır. Sikloidal hız profilinin yavaşlama süresinin tek eksenli manipülatörde kalıcı titreşimini azaltmak için önemli olduğu gözlemlenmiştir.

$\mathrm{Bu}$ çalışmada, iki eksenli esnek bir manipülatörün titreşim kontrolü sunulmuştur. İki eksenli esnek manipülatör için, benzetim sonuçları ANSYS APDL dili kullanılarak verilmiştir. Benzetim sonuçlarını doğrulamak için deneysel bir sistem kullanılmıştır. Uç nokta için çeşitli başlangıç ve durma pozisyonları çeşitli trapez hareket profilleri ile birlikte değerlendirilmiştir. Doğal frekansa dayalı uygun bir yavaşlama zamanının seçilmesi fikri, iki eksenli esnek manipülatöre kadar uzanır. İki eksenli manipülatörün doğal frekansı hareket ettikçe değişir. İki eksenli manipülatörün durdurma noktasındaki doğal frekansına dayanan trapez hız profilinin yavaşlama süresinin artık titreșimi azaltmak için önemli olduğu gözlemlenmiştir. MATLAB ve ANSYS tarafindan elde edilen benzetim sonuçlarının karşılaştırılması ve deney sonuçları iyi bir şekilde örtüştügünü göstermektedir.

$\mathrm{Bu}$ çalışmada verilen benzetim ve titreşim kontrolü yaklaşımı için modelleme prosedürü, çok-eksenli seri robotlar veya Kartezyen robotlar gibi çok gövdeli esnek sistemlerin dinamik analizi için kullanılabilir. Bu çalışmanın sonuçları, kalıcı titreşimleri kontrol etmek için tut-bırak uygulamalarında kullanılabilir.

\section{Kaynakça}

[1] Benosman M., LeVey G. 2004. Control of flexible manipulators: A survey. Robotica, Cilt. 22, s. 533545.

[2] Fung T.C. 1997. Unconditionally stable higher-order Newmark methods by sub-stepping procedure. Computer Methods in Applied Mechanics and Engineering, Cilt. 147, s. 61-84.

[3] Owren B., Simonsen H.H. 1995. Alternative integration methods for problems in structural dynamics. Computer Methods in Applied Mechanics and Engineering, Cilt. 122, s. 1-10.

[4] Zhang L., Zhu J.W., Zheng Z. 1999. The stochastic Newmark algorithm for random analysis of multi-degree-of-freedom nonlinear systems. Computers and Structures, Cilt. 70, s. 557-568.

[5] Karagülle H., Malgaca L., Öktem H.F. 2004. Analysis by active vibration control in smart structures by ANSYS, Smart Materials and Structures, Cilt. 13, s. 661-667.

[6] Dwivedy S.K., Eberhard P. 2006. Dynamic analysis of flexible manipulators, a literature review. Mechanism and Machine Theory, Cilt. 41, s. 749-777.

[7] Shin H.C., Choi S.B. 2001. Position control of a two link flexible manipulator featuring piezoelectric actuators and sensors. Mechatronics, Cilt. 11, s. 707-729.

[8] Gurses K., Bradley J.B., Edward J.P. 2009. Vibration control of a single-link flexible manipulator using an array of fiber optic curvature sensors and PZT actuators. Mechatronics Cilt. 19, s. 167-177. 
[9] Mirzaee E., Eghtesad M., Fazelzadeh S.A. 2010. Maneuver control and active vibration suppression of a two-link flexible arm using a hybrid variable structure/Lyapunov control design. Acta Astronautica, Cilt. 67, s. 1218-1232.

[10] Zhang Q., Li J., Zhang J., Zhang J. 2017. Smooth adaptive sliding mode vibration control of a flexible parallel manipulator with multiple smart linkages in modal space. Journal of Sound and Vibration. Cilt. 411, s. 1-19.

[11] Pedro J.O., Smith R.V. 2017. RealTime Hybrid PID/ILC Control of Two-Link Flexible Manipulators. IFAC-PapersOnline. Cilt. 50, s. 145-150.

[12] Park K.J. 2004. Flexible robot manipulator path design to reduce the endpoint residual vibration under torque constraints. Journal of Sound and Vibration, Cilt. 275, s. 1051-1068.

[13] Abe A. 2009. Trajectory planning for residual vibration suppression of a two-link rigidflexible manipulator considering large deformation. Mechanism and Machine Theory, Cilt. 44, s. 1627-1639.

[14] Green A., Sasiadek J.Z. 2004. Dynamics and Trajectory Tracking Control of a Two-Link Robot Manipulator. Journal of Vibration and Control, Cilt. 10, s. 1415-1440.

[15] Singer N.C., Seering W.P. 1990. Preshaping command inputs to reduce system vibration. Journal of Dynamic Systems, Measurement and Control, Cilt. 112, s. 76-82.

[16] Singhose W. 2009. Command shaping for flexible systems: a review of the first 50 years. International Journal of Precision
Engineering and Manufacturing, Cilt. 10, s. 153-168.

[17] Ouyang Y., He W., Li X. 2017. Reinforcement learning control of a single- link flexible robotic manipulator. IET Control Theory. Cilt. 11(9), s. 1426-1433.

[18] Ankarali A., Diken H. 1997. Vibration Control Of An Elastic Manipulator Link. Journal of Sound and Vibration, Cilt. 204, s. 162-170.

[19] Mimmi G., Pennacchi P. 2001. Pre-shaping Motion Input for a Rotating Flexible Link. International Journal of Solids and Structures, Cilt. 38, s. 2009 2023.

[20] Shan J., Liu H.T., Sun S. 2005. Modified input shaping for a rotating single-link flexible manipulator. Journal of Sound and Vibration,Cilt. 285, s. 187207.

[21] Shin K., Brennan M.J. 2008. Two simple methods to suppress the residual vibrations of a translating or rotating flexible cantilever beam. Journal of Sound and Vibration, Cilt. 312, s. 140 150.

[22] Ozer A., Semercigil S.E. 2008. An event-based vibration control for a two-link flexible robotic arm: Numerical and experimental observations. Journal of Sound and Vibration, Cilt. 313, s. 375394.

[23] Karagülle H., Malgaca L., Dirilmiș M., Akdağ M., Yavuz Ş. 2017. Vibration control of a two-link flexible manipulator. Journal of Vibration and Control, Cilt. 23, s. 2023-2034.

[24] ANSYS. 2018. Web adresi: http:// http://www.ansys.com/academi c. Erișim Tarihi: 20.01.2018

[25] Thomson W.T., \& Dahleh M.D. (1988). Theory of Vibration with 
Ş. Yavuz / İki Eksenli Esnek bir Manipülatörün ANSYS APDL ile Modellenmesi ve Titreşim Kontrolü

Applications 3rd edition.

Englewood Cliffs: Prentice-Hall.

[26] MicroStrain Inc. 2015. Web adresi:

http://www.microstrain.com/wi

reless/sensors. Erişim tarihi: 20.01.2018. 